Journal Club

Editor's Note: These short, critical reviews of recent papers in the Journal, written exclusively by graduate students or postdoctoral fellows, are intended to summarize the important findings of the paper and provide additional insight and commentary. For more information on the format and purpose of the Journal Club, please see http://www.jneurosci.org/misc/ifa_features.shtml.

\title{
Endocannabinoid Signaling Alters Internal Programming of Neuronal Fate Specification
}

\author{
Eduardo Bouth Sequerra, ${ }^{1,8}$ Staci Cates, ${ }^{4,5,8}$ Monica Moreno, ${ }^{2,3,6,8}$ Jordan Lang, ${ }^{7,8}$ Lori A. Orosco, ${ }^{4,8}$ and Kira Spencer ${ }^{1,5,8}$ \\ Departments of ${ }^{1}$ Physiology and Membrane Biology, ${ }^{2}$ Immunology, ${ }^{3}$ Neurology, and ${ }^{4}$ Medical Pathology and Laboratory Medicine, and ${ }^{5}$ Neuroscience Graduate \\ Group, ${ }^{6}$ Immunology Graduate Group, ${ }^{7}$ Biochemistry, Molecular, Cellular and Developmental Biology Graduate Group, University of California, Davis, Davis, \\ California 95616, and ${ }^{8}$ Shriners Hospital for Children—Northern California, University of California Davis School of Medicine, Sacramento, California 95817
}

Review of Díaz-Alonso et al.

The mature neocortex consists of 6 layers, which develop radially in an inside-out fashion wherein the deeper layers, closest to the proliferative regions, develop first, followed by the superficial layers (Angevine and Sidman, 1961). Differentiating neurons and progenitors express transcription factors unique to their final cortical layer destination (for review, see Molyneaux et al., 2007). Until recently, it was believed that a single dorsal telencephalic embryonic progenitor cell could generate excitatory cortical neurons that inhabit every cortical layer. This idea is supported by data showing that single precursor cells in vitro divide to form clones (somewhat resembling a radial clone in vivo) that contain all cortical layer neuronal types, except for inhibitory neurons (Shen et al., 2006). However, more recent fate-mapping and clonal analysis studies have revealed that there are at least two subpopulations of telencephalic progenitors whose distinct cell fates are determined by their expression of the transcription factor Cux2. Franco et al. (2012) showed that Cux2 ${ }^{+}$precursors give rise to superficial-layer neurons, whereas $\mathrm{Cux} 2^{-}$precursors give rise to deep-layer neurons. The identification of

Received Jan. 20, 2013; revised Feb. 21, 2013; accepted Feb. 25, 2013.

Correspondence should be addressed to Eduardo Bouth Sequerra, 2425

Stockton Blvd., Shriners Hospital for Children-Research, Sacramento, CA 95817. E-mail: ebsequerra@ucdavis.edu.

DOI:10.1523/JNEUROSCI.0274-13.2013

Copyright $\odot 2013$ the authors $\quad 0270-6474 / 13 / 335437-02 \$ 15.00 / 0$ these unique sublineages indicates that superficial- and deep-layer neurons do not arise from the same cortical progenitor pool as previously thought.

Suzuki et al. (2012) observed that bird telencephalic progenitors are segregated, as in mammals, suggesting that precursor segregation may be a common feature of all amniotes. Similar to findings in mice, when bird progenitors are cultured at clonal density, the clones generate neurons expressing homologs of both superficial and deep-layer mammalian transcription factors (Shen et al., 2006; Suzuki et al., 2012). Although each precursor holds the potential to generate both superficial and deep-neuronal phenotypes in mammals and birds, something in situ prevents them from doing so.

While this segregation between clones appears to be evolutionarily conserved, the mechanisms controlling it are mostly unknown. Transplantation studies demonstrated the influence of external signals on layer specification by showing that the fate of a cell can be changed under certain conditions. Extrinsic factors present within the host tissue environment influence the fate of progenitors from younger embryos before their last S-phase. In contrast, progenitors that have passed through S-phase maintain the identity from the donor tissue (McConnell and Kaznowski, 1991). These findings support the existence of extrinsic signals in the proliferative region that can influence progenitors to commit to layerspecific phenotypes; however, the progeni- tors have a limited window in which they respond to these signals.

Only a few examples of these extrinsic signals have been identified so far. The first extrinsic signaling molecule implicated in cortical-layer fate specification was brain-derived neurotrophic factor (BDNF) (Fukumitsu et al., 2006). Fukumitsu et al. (2006) showed that BDNF injections alter the position and gene expression profiles of layer IV neurons to that of deeper-layer neurons. Therefore, it is possible that BDNF is one molecule that regulates segregation between clones in the ventricular zone (VZ).

While extrinsic factors that influence layer specification are beginning to be identified, the specific effects on the transcriptional program are still unknown. DíazAlonso et al. (2012) showed that signaling derived from $\mathrm{CB}_{1}$ activation prevents Satb2mediated repression of the Ctip2 promoter, leading to deep-layer neuronal differentiation (Fig. 1). It is possible that $\mathrm{CB}_{1}$ activation is one mechanism contributing to the segregation of the $\mathrm{Cux} 2^{-}$population described by Franco et al. (2012; Fig. 1A). An interesting experiment would be to treat telencephalic slices, from reporter mice in which Cux2-lineage cells are labeled (Franco et al., 2012) with a $\mathrm{CB}_{1}$ agonist. These studies would reveal whether $\mathrm{Cux} 2^{+}$clones can be reprogrammed to become deep-layer neurons (Fig. $1 C$ ). It is clear that overactivation of $\mathrm{CB}_{1}$ leads to reduction of Satb ${ }^{+}$cells. However, it is 
still unclear whether the loss of Satb2 causes respecification to a deep-layer phenotype, or whether the superficial-layer specification is retained despite a reduction in Satb2 expression.

Díaz-Alonso et al. (2012) also provide insight on the effect of extrinsic signaling on postmitotic differentiation. To dissect $\mathrm{CB}_{1}$ effects after proliferation, the authors used Nex- $\mathrm{CB}_{1}{ }^{-1-}$ mice, in which $\mathrm{CB}_{1}$ is conditionally knocked-out in postmitotic neurons. They found that after cell cycle exit, removal of the $\mathrm{CB}_{1}$ gene still led to a decrease in the number of Ctip2 ${ }^{+}$neurons, deficits in their subcortical projections, and impaired corticospinal motor function (Fig. 1D; Díaz-Alonso et al., 2012). Unlike transcription factors that are expressed following an external trigger, Ctip2 expression requires continuous $\mathrm{CB}_{1}$ signaling even after cell cycle exit.

The work by Díaz-Alonso et al. (2012) indicates that activating $\mathrm{CB}_{1}$ interferes with Satb2's regulation of the Ctip2 promoter; however, the intracellular mechanism through which this occurs is unknown. $\mathrm{CB}_{1}$ is a G-protein-coupled receptor which signals through $\mathrm{G}_{\mathrm{i} / \mathrm{o}}$ and has several downstream targets including adenylyl cyclase, MAPK, and c-Jun as well as $\mathrm{K}^{+}$and $\mathrm{Ca}^{2+}$ ion channels (Castillo et al., 2012). Thus, there are many possible mechanisms through which $\mathrm{CB}_{1}$ may influence Satb2. Spontaneous activity has been shown to regulate glutamatergic differentiation in the developing spinal cord via the transcription factor Tlx3 (Marek et al., 2010). Ion channels are a downstream target of $\mathrm{CB}_{1}$, so it is possible that $\mathrm{CB}_{1}$ alters spontaneous activity to regulate Satb2 expression in neuronal precursors.

Díaz-Alonso et al. (2012) have described an interaction between extrinsic signaling and the corticospinal neuronal transcriptional programs. While questions remain pertaining to molecular mechanisms of the signaling pathway, it is now apparent that continuous signaling after mitosis is necessary for proper neuronal differentiation. Identifying the source of endocannabinoid release will be required to achieve a more complete understanding of how clones become segregated in the VZ.

The authors show that loss of $\mathrm{CB}_{1}$ signaling results not only in defects in neuronal differentiation, but also that these changes manifest in skilled-motor deficits in adulthood. While they did not explore the behavioral outcomes from $\mathrm{CB}_{1}$ overactivation, it is possible there would be cognitive deficits resulting from the decrease in superficial-layer neurons. Clini-
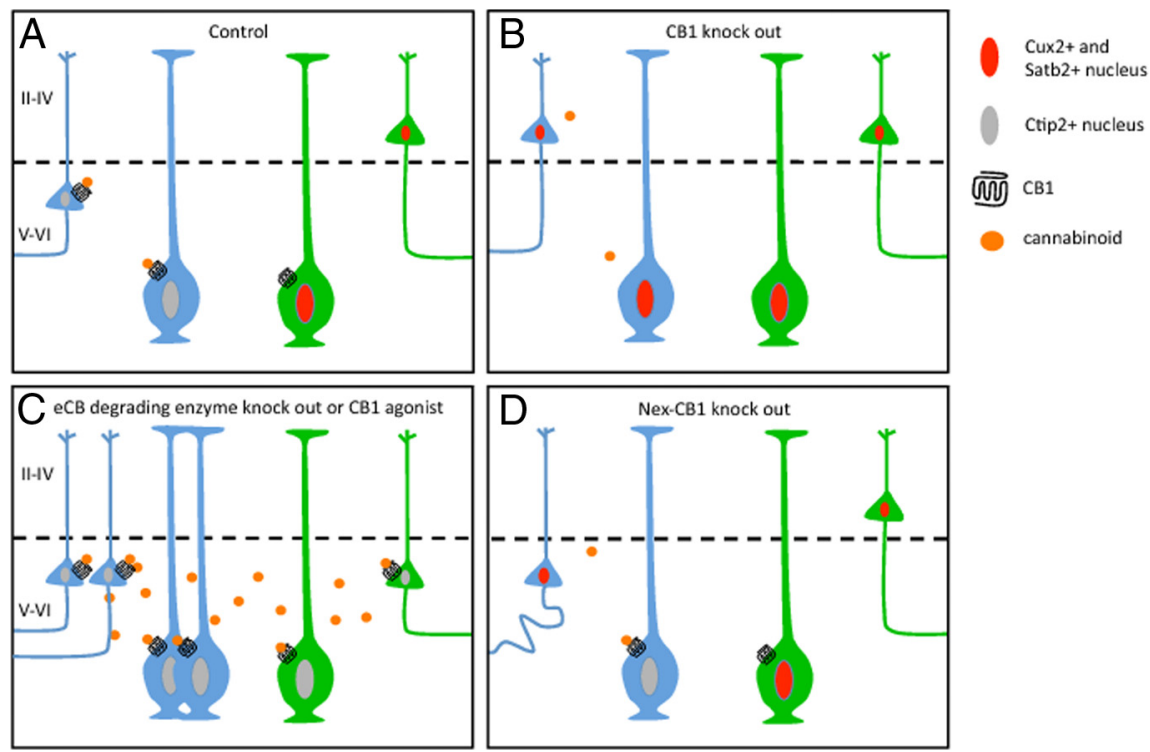

Figure 1. CB1-mediated control of Ctip2 ${ }^{+}$clone segregation. $A$, CB1 activation in radial glia clones (blue cells) leads to inhibition of Satb2-mediated suppression of Ctip2 expression, and this clone generates deep-layer neurons. The clones that do not experience (B1 activation (green cells) generate superficial layers, such as Cux2 ${ }^{+}$(and probably Satb2 ${ }^{+}$) clones. B, Knock-out of CB1 leads to the failure to induce Ctip2 expression and thus the differentiation of deep-layer neurons. $C$, Increased activation of CB1 receptors increases the number of progenitors generating deep-layer neurons. This might happen either by increasing Ctip2 ${ }^{+}$progenitors (blue radial glia) or by respecifying other progenitors (e.g., Cux2 ${ }^{+}$clones; green cells), which remains to be determined. D, Knock-out of CB1 expression after mitosis also reduces Ctip2 expression. Although cell fates do not seem to respecify, this leads to projection defects.

cal evidence suggests that cannabinoid exposure during development results in cognitive deficits (Jutras-Aswad et al., 2009). Thus, balanced $C_{1}$ signaling is important for proper cortical development. There are many common substances that can alter endocannabinoid signaling such as organophosphorous pesticides, ethanol, and tetrahydrocannabinol (THC), the principal constituent of marijuana. Further investigation into $\mathrm{CB}_{1}$-dependent developmental processes will be important for understanding the consequences of exogenous cannabinoid exposure during pregnancy.

\section{References}

Angevine JB Jr, Sidman RL (1961) Autoradiographic study of cell migration during histogenesis of cerebral cortex in the mouse. Nature 192:766-768. CrossRef Medline

Castillo PE, Younts TJ, Chávez AE, Hashimotodani Y (2012) Endocannabinoid signaling and synaptic function. Neuron 76:70-81. CrossRef Medline

Díaz-Alonso J, Aguado T, Wu CS, Palazuelos J, Hofmann C, Garcez P, Guillemot F, Lu HC, Lutz B, Guzmán M, Galve-Roperh I (2012) The CB(1) cannabinoid receptor drives corticospinal motor neuron differentiation through the Ctip2/ Satb2 transcriptional regulation axis. J Neurosci 32:16651-16665. CrossRef Medline

Franco SJ, Gil-Sanz C, Martinez-Garay I, Espinosa A, Harkins-Perry SR, Ramos C, Müller U (2012) Fate-restricted neural progenitors in the mammalian cerebral cortex. Science 337: 746-749. CrossRef Medline

Fukumitsu H, Ohtsuka M, Murai R, Nakamura H, Itoh K, Furukawa S (2006) Brain-derived neurotrophic factor participates in determination of neuronal laminar fate in the developing mouse cerebral cortex. J Neurosci 26: 13218-13230. CrossRef Medline

Jutras-Aswad D, DiNieri JA, Harkany T, Hurd YL (2009) Neurobiological consequences of maternal cannabis on human fetal development and its neuropsychiatric outcome. Eur Arch Psychiatry Clin Neurosci 259:395412. CrossRef Medline

Marek KW, Kurtz LM, Spitzer NC (2010) cJun integrates calcium activity and tlx 3 expression to regulate neurotransmitter specification. Nat Neurosci 13:944-950. CrossRef Medline

McConnell SK, Kaznowski CE (1991) Cell cycle dependence of laminar determination in developing neocortex. Science 254:282-285. CrossRef Medline

Molyneaux BJ, Arlotta P, Menezes JR, Macklis JD (2007) Neuronal subtype specification in the cerebral cortex. Nat Rev Neurosci 8:427-437. CrossRef Medline

Shen Q, Wang Y, Dimos JT, Fasano CA, Phoenix TN, Lemischka IR, Ivanova NB, Stifani S, Morrisey EE, Temple S (2006) The timing of cortical neurogenesis is encoded within lineages of individual progenitor cells. Nat Neurosci 9:743-751. CrossRef Medline

Suzuki IK, Kawasaki T, Gojobori T, Hirata T (2012) The temporal sequence of the mammalian neocortical neurogenetic program drives mediolateral pattern in the chick pallium. Dev Cell 22:863-870. CrossRef Medline 